\title{
An open-label trial of divalproex sodium extended release for pediatric bipolar spectrum disorder in children age 6 - 12 years*
}

\author{
Janet Wozniak $^{1,2}$, Paul Hammerness ${ }^{1,2}$, Robert Doyle ${ }^{1,2}$, Gagan Joshi ${ }^{1,2}$, K. Yvonne Woodworth ${ }^{1}$, \\ Joseph Biederman ${ }^{1,2}$ \\ ${ }^{1}$ Pediatric Psychopharmacology Research Unit, Massachusetts General Hospital, Boston, USA \\ ${ }^{2}$ Department of Psychiatry, Harvard Medical School, Boston, USA \\ Email:jwozniak@partners.org
}

Received 13 January 2012; revised 12 February 2012; accepted 9 March 2012

\begin{abstract}
Objective: To estimate the rate of response to divalproex sodium extended release in pediatric bipolar spectrum disorder in young children age 6 - 12. Methods: This was an 8-week, open-label treatment of youth with DSM-IV bipolar disorder with divalproex sodium extended release (ER) monotherapy. Severity of mania was assessed weekly with the Young Mania Rating Scale (YMRS). Results: The sample was $8.9 \pm$ 2.0 years of age and predominantly male $(83 \%)$. At study entry the mean YMRS score was $26.3 \pm 4.5$. Of the 18 subjects enrolled, 7 (39\%) completed the 8 week course. We failed to find a clinically or statistically significant improvement with divalproex sodium ER. Pre-post comparisons at endpoint (LOCF) indicated an average response reduction of $6.1 \pm 2.6$ in the YMRS to a mean of $20.3 \pm$ 8.1. Weight increased by $1.36 \pm 0.7 \mathrm{~kg}(p=0.08)$ from baseline to endpoint. Conclusion. Divalproex sodium ER monotherapy was associated with poor tolerability, was associated with clinically concerning weight gain but had modest therapeutic benefits in the management of symptoms of mania and depression in children with pediatric bipolar disorder.
\end{abstract}

Keywords: Bipolar Disorders; Pediatric; Psychopharmacology; Open-Label

\section{INTRODUCTION}

Childhood bipolar disorder (BPD) is among the most severely disabling psychiatric conditions affecting children [1-3]. Early onset of the disorder is associated with great severity of illness and high levels of psychosis,

${ }^{*}$ Role of funding source: the study sponsors were not involved in the study design, data collection, analysis, or writing of the manuscript. mixed mania, and severe aggression [4-6]. To date, few medications are approved for the treatment of pediatric onset bipolar disorder: lithium and the atypical antipsychotic medications risperidone, aripiprazole, and quetiapine for ages 10 to 17, and olanzapine for ages 13 to 17 .

One of the most widely used pharmacological treatments in adult bipolar disorder is divalproex sodium [7-9]. An emerging literature has examined the safety and efficacy of divalproex sodium in children and adolescents with bipolar disorder. In a 6-week open-label trial, Kowatch et al. [10] first reported that $40 \%$ of 15 pediatric subjects treated with divalproex sodium were improved. Wagner et al. [11] reported that $61 \%$ of 36 subjects treated with divalproex sodium showed a greater than $50 \%$ improvement from the baseline Mania Rating Scale (MRS) score. In a 6-month open label prospective trial of divalproex sodium monotherapy, Pavuluri et al. [12] reported that $73 \%$ of 34 pediatric subjects had at least a $50 \%$ reduction in YMRS score and a Child Depression Rating Scale (CDRS) score $\leq 40$. Scheffer et al. [13] reported that $80 \%$ of 40 pediatric subjects treated with divalproex sodium had at least a $50 \%$ reduction in YMRS score during an 8-week open-label trial. In two adolescent studies Delbello et al found that $40 \%$ [14] and 53\% [15] of subjects responded to divalproex sodium monotherapy.

However, many of the studies in the extant literature used additional medicines for mood stabilization, and treatment with divalproex sodium was associated with poor tolerability in children. With the exception of the adolescent studies [14,15] and Scheffer et al., [13] the number of subjects completing short-term trials of divalproex sodium monotherapy for pediatric bipolar disorder has been less than $50 \%[10,11]$. An extended release formulation of divalproex sodium is available. By minimizing sharp fluctuations between peaks and troughs in serum concentration of divalproex sodium administered b.i.d., this once a day formulation may improve tolerabil- 
ity as well as adherence [16]. In the double blind conditions of divalproex sodium extended release, a treatment effect was not observed and adverse events were similar to those observed with placebo [17]. However, this study included Bipolar I youth age 10 - 17, with Young Mania Rating Scale score greater than 20, leaving open the possibility that younger children or children with less severe illness may have a more robust response.

The main objective of this study was to evaluate the safety of and efficacy to the new extended release formulation of divalproex sodium in the treatment of pediatric bipolar disorder in an open label trial in youth age 6 12 years, including all bipolar spectrum subjects and with an inclusion criteria of Young Mania Rating Scale greater than 15 . To this end we conducted an open label prospective 8-week study of divalproex sodium extended release (ER) monotherapy in children with bipolar disorder. We hypothesized that divalproex sodium ER will be efficacious and well tolerated in this population.

\section{PATIENTS AND METHODS}

Male or female subjects, 6 - 12 years of age were included in the trial. Each subject met criteria for bipolar I disorder or bipolar disorder NOS and were currently displaying manic, or mixed symptoms (with or without psychotic features) according to the DSM-IV based on clinical assessment and confirmed by structured diagnostic interview (Kiddie Schedule of Affective Disorders and Schizophrenia Epidemiological Version). Bipolar NOS was defined as having severe mood disturbance, which meets DSM-IV Criteria A for bipolar disorder but fewer elements in Criteria B or having episodes of less than one week in duration. In addition, at study entry the subject must have had a score of 15 or greater on the Young Mania Rating Scale (YMRS) [18,19].

Prior to enrollment, participants were screened by phone to describe study procedures and evaluate study eligibility. Study procedures were approved by the Massachusetts General Hospital (MGH) human subjects Internal Review Boards (IRBs). Consent was obtained from a parent and the child provided written assent.

We excluded subjects with any serious, unstable medical illness including hepatic, renal, gastroenterologic, respiratory, cardiovascular, endocrinologic, neurologic, immunologic, or hematologic disease. Subjects who were judged to be at serious suicidal risk were also excluded from participation. No patient was entered into the study if they were adequately stabilized on an antimanic therapy. Mood stabilizers, anticonvulsants, neuroleptics and antidepressants were not allowed during this study.

Given the strong overlap of juvenile bipolar disorder with attention deficit hyperactivity disorder (ADHD), methylphenidate hydrochloride, dextroamphetamine sul- fate and mixed amphetamine salts were allowed during the study if, in the clinician's judgment, it was in the best interest of the subject to continue this treatment or if the subject's parent did not wish to stop stimulant treatment and only if the patient had been on a stable dose for at least 30 days. One subject was receiving stimulants at study entry and this medication (Adderall XR $20 \mathrm{mg} /$ day) was maintained throughout the trial. The use of benzodiazepine lorazepam was permitted during the study and was used in two subjects for one week and in one subject for two weeks. Non-pharmacological treatments such as individual, family, or group therapy were allowed if they were in place before the subject joined the study and if the therapy regimen remained the same throughout the study.

Study medication was initiated at $10-15 \mathrm{mg} / \mathrm{kg} / \mathrm{day}$ and was increased by $5-10 \mathrm{mg} / \mathrm{kg}$ weekly. Subjects were titrated upwards only if treatment was tolerated, trough serum concentrations did not exceed $100 \mathrm{mcg} / \mathrm{ml}$, and if improvement was insufficient (CGI-Improvement > 2).

Severity of symptoms of mania was assessed weekly with the YMRS. Psychotic symptoms were assessed at baseline and endpoint with the Brief Psychiatric Rating Scale (BPRS) [20]. To assess clinically significant severity and improvement relative to baseline, we used the NIMH Clinical Global Impression (CGI) severity (CGI-S), and improvement (CGI-I) scales [21]. CGI severity and improvement were assessed separately for depression, mania, conduct disorder, and ADHD. The score for the CGI-S ranges from 1 (normal, not at all ill) to 7 (among the most extremely ill patients). The score for the CGI-I ranges from 1 (very much improved) to 7 (very much worse). Safety was assessed at each visit using spontaneous reports of treatment-emergent adverse events, changes in vital signs and laboratory measures. Rates of subjectively reported adverse effects reflect their occurrence more than once in the clinical trial. Blood pressure and weight were recorded at each visit. ECG, prolactin, glucose and lipid levels were obtained at baseline and post treatment.

\section{Statistical Analysis}

Generalized estimating equations were used to analyze the eight repeated measures of the study. All analyses were intention to treat (ITT) with the last observation (LOC) carried forward for subjects that did not complete the full study schedule. Statistical significance was determined at $\mathrm{p}<0.05$.

\section{RESULTS}

The 18 children enrolled in the study were $8.9 \pm 2.0$ years of age and predominantly male $(83 \%, \mathrm{~N}=15)$. At study entry the mean YMRS score was $26.3 \pm 4.5$. In addition to a CGI-S score of 3 or greater for mania, clinically relevant 
symptoms (CGI-Severity score $\geq 3$ ) of depression (50\%, $\mathrm{N}=9), \operatorname{ADHD}(100 \%, \mathrm{~N}=18)$ and conduct disorder $(22 \%, \mathrm{~N}=4)$ were also prevalent at baseline assessment. Of the 18 subjects enrolled, only 7 (39\%) completed the 8 -week course; dropouts were due to adverse effects $(\mathrm{N}=$ $7)$ or failure to return for follow-up $(\mathrm{N}=4)$. The mean dose of study medication at study endpoint was $847.2 \pm$ $486.1 \mathrm{mg} /$ day. At study endpoint, serum levels were available for 15 of the 18 subjects and the average was $84.9 \pm$ $40.6 \mathrm{mcg} / \mathrm{ml}$.

Figure 1 shows there was $6.1 \pm 11.0$ point reduction in the YMRS at study endpoint (week 8 or LOCF). At study endpoint, $50 \%(\mathrm{~N}=9)$ of subjects had a $30 \%$ reduction in baseline YMRS scores and 22\% $(\mathrm{N}=4)$ had a $50 \%$ reduction in baseline YMRS scores. As shown in Table 1, baseline to endpoint analysis indicated a clinically modest but statistically significant reduction on the YMRS, the BPRS, and the CDRS. The mean values of these rating scales at endpoint indicated persistent residual symptoms of mania and depression. As shown in Figure 2, 55\% of subjects were rated as much or very much improved at study endpoint on the CGI-I Mania. The rates of response in symptoms of depression and ADHD were low (Figure 2).

Post hoc analysis comparing results between those with and without therapeutic serum levels of divalproex sodium showed very similar results on primary measures: $6.9 \pm 9.5$ point reduction of YMRS score, a 30\% reduction in YMRS scores in 58\%, and a $50 \%$ reduction in YMRS scores in $17 \%$ of the sample. Post hoc analysis of subjects who completed the trial $(\mathrm{N}=7)$ showed that

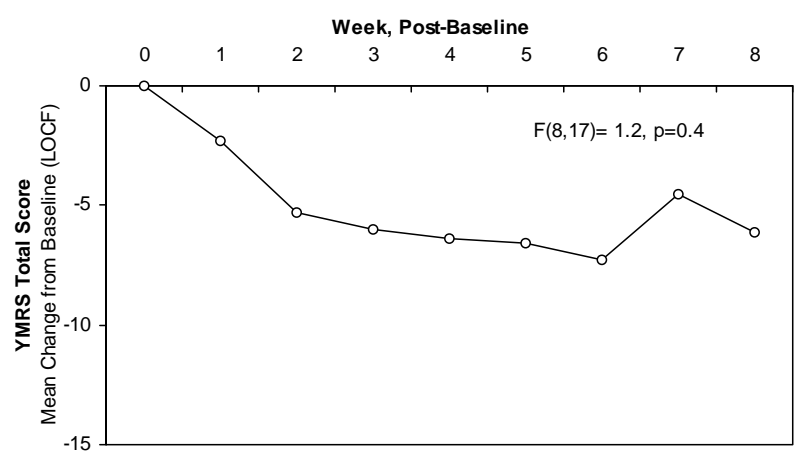

Figure 1. Change in YMRS scores in open study over 8 weeks.

Table 1. Rating scale scores at baseline and endpoint.

\begin{tabular}{cccc}
\hline & Baseline & Endpoint & \\
\cline { 2 - 3 } & Mean $\pm \mathrm{SD}$ & Mean $\pm \mathrm{SD}$ & Statistic \\
\hline YMRS & $26.3 \pm 4.5$ & $20.3 \pm 8.1$ & $\begin{array}{c}\mathrm{F}(1,17)=5.3, \\
\mathrm{p}=0.03\end{array}$ \\
BPRS & $41.6 \pm 8.0$ & $34.3 \pm 12.0$ & $\begin{array}{c}\mathrm{F}(1,17)=8.9, \\
\mathrm{p}=0.008\end{array}$ \\
CDRS & $38.5 \pm 14.2$ & $30.8 \pm 10.1$ & $\mathrm{~F}(1,17)=4.8$, \\
$\mathrm{p}=0.04$
\end{tabular}

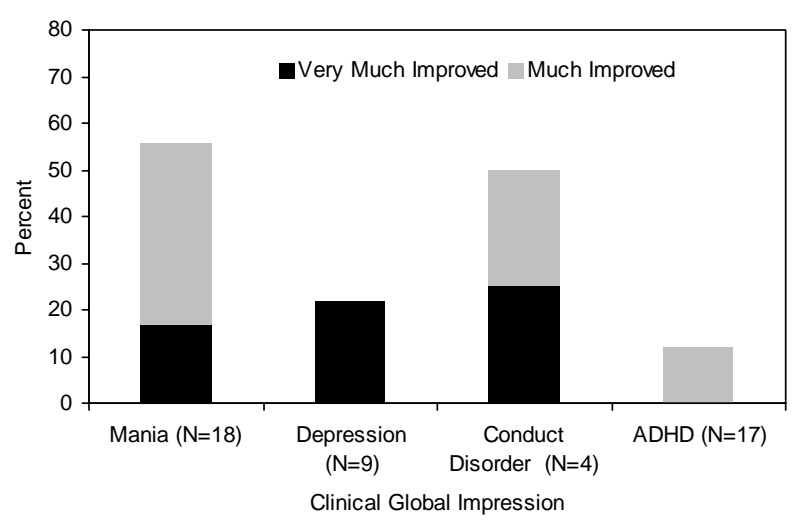

Figure 2. CGI rated improvement in mania and psychiatric comorbidity.

these subjects had an average YMRS reduction at end point of $13.3 \pm 3.5(\mathrm{p}=0.001)$. Yet, even in this subgroup, only $2(28 \%)$ registered a $50 \%$ improvement on the YMRS.

As illustrated in Figure 3, the most commonly reported adverse effects associated with divalproex sodium ER that occurred more than once in the trial, were GI complaints $(33 \%)$, common colds $(27 \%)$, and sedation $(22 \%)$. There were no significant differences between baseline and endpoint in metabolic variables (Table 2). Weight gain was statistically insignificant measured pre and post trial, but concerning given the young age of the subjects $(1.4 \pm$ $3.0 \mathrm{~kg})$.

\section{DISCUSSION}

This was a prospective, open-label treatment trial of divalproex sodium ER monotherapy for the treatment of mania in $\mathrm{N}=18$ youth aged $6-12$ years with bipolar spectrum disorder. Intent to treat analysis showed modest improvements from baseline to endpoint in symptoms of mania or depression. Notably, the rate of completion was low with only $7(39 \%)$ of enrolled subjects completing the 8 -week trial and the rate of dropout due to adverse effects was high (39\%, $\mathrm{N}=7)$. Divalproex sodium ER was not free from weight gain, with average gain of $1.4 \pm 3.0 \mathrm{~kg}$ over only 8 weeks in children average age of 9 years.

In our study, only $22 \%$ of subjects had a $50 \%$ reduction in YMRS. This finding stands in contrast with higher response rates reported in the literature in which $40 \%$ $80 \%$ of subjects showed $50 \%$ reduction in YMRS scores. $[10,13,22-25]$ The double blind study of divalproex sodium ER found a modest decrease in YMRS of only 8.8, similar to placebo, 7.9 [17]. However, with the exception of Sheffer et al., [13] previous trials of children with bipolar disorder that demonstrated a stronger clinical response allowed for the concomitant use of antipsychotics or other mood stabilizers $[11,12,26]$. The only studies to demonstrate a positive response with divalproex 
Table 2. Metabolic, cardiovascular variables and weight at baseline and endpoint.

\begin{tabular}{cccc}
\hline & Baseline & Endpoint & Statistic \\
\cline { 2 - 4 } & Mean \pm SD & Mean \pm SD & F $(1.15)=2.2, \mathrm{p}=0.2$ \\
Cholesterol (mg/dL) & $155.9 \pm 23.8$ & $142.8 \pm 26.3$ & $\mathrm{~F}(1.15)=1.0, \mathrm{p}=0.3$ \\
High Density Lipoprotein (mg/dL) & $49.3 \pm 6.7$ & $52.4 \pm 7.3$ & $\mathrm{~F}(1.15)=1.6, \mathrm{p}=0.2$ \\
Low Density Lipoprotein (mg/dL) & $80.1 \pm 24.9$ & $68.4 \pm 21.4$ & $\mathrm{~F}(1.17)=1.2, \mathrm{p}=0.3$ \\
Systolic Blood Pressure (mmHg) & $103.6 \pm 11.9$ & $106.7 \pm 12.4$ & $\mathrm{~F}(1.17)<0.01, \mathrm{p}=0.9$ \\
Diastolic Blood Pressure (mmHg) & $61.5 \pm 10.3$ & $61.5 \pm 8.9$ & $\mathrm{~F}(1.17)=1.8, \mathrm{p}=0.2$ \\
Pulse (bpm) & $93.0 \pm 13.3$ & $89.9 \pm 8.6$ & $\mathrm{~F}(1.17)=3.5, \mathrm{p}=0.08$ \\
\hline Weight $(\mathrm{kg})$ & $34.9 \pm 17.6$ & $36.2 \pm 19.4$ &
\end{tabular}

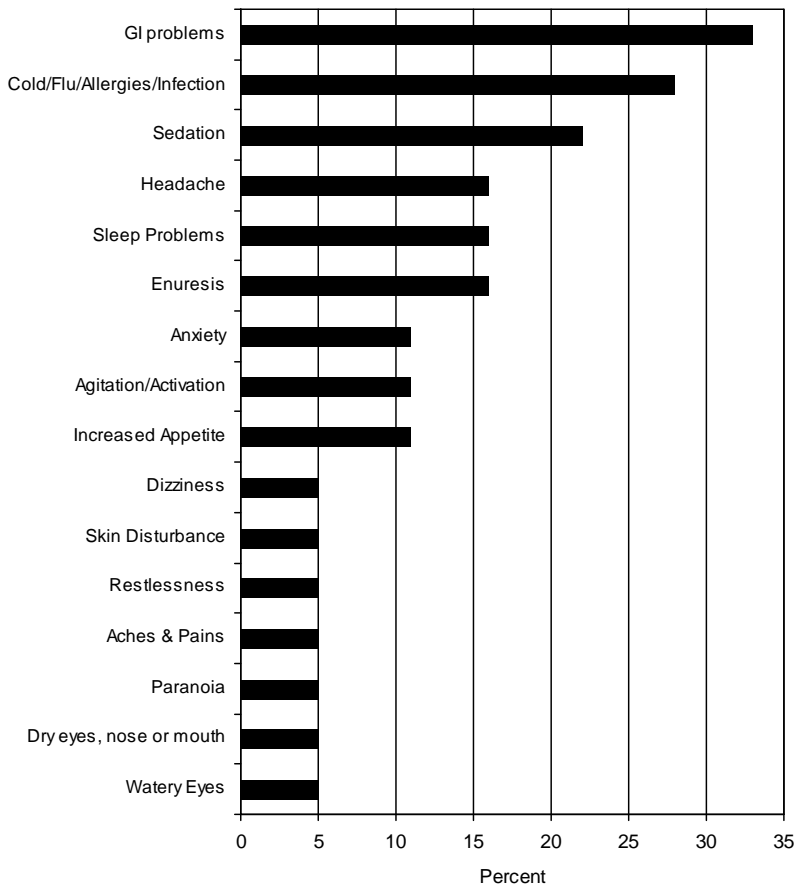

Figure 3. Rate of adverse events ( $>1$ occurrence).

sodium monotherapy were those conducted by DelBello et al. $[14,15]$ However, these studies were in adolescents and also documented that divalproex sodium monotherapy was inferior to both divalproex sodium + quetiapine [15] and quetiapine monotherapy [14]. Thus, our findings, consistent with the double blind findings, may be different from the previous literature because we did not allow the use of any other mood stabilizing medications.

In our data, completers demonstrated a more clinically significant response than those who dropped and those studies with the highest rate of completion also had the highest rate of response $[10,13,22]$. Since most subjects who dropped from our study did so due to adverse effects (7 of 11 discontinuations), divalproex sodium may be effective for the subgroup that can tolerate this medication.
More work is needed to further evaluate the efficacy and tolerability of different formulations of divalproex in the treatment of pediatric bipolar disorder.

The modest therapeutic effects observed in our study were not due to dosing or levels. The average serum concentration of divalproex sodium of $84.9 \pm 40.6 \mathrm{mcg} / \mathrm{ml}$ is consistent with the extant literature, which ranged from 79.8 [25] to $109 \mathrm{mcg} / \mathrm{ml}$ [12]. Even when we limited our results to the subset that attained therapeutic levels in our sample (i.e. $>50 \mathrm{mcg} / \mathrm{ml}$ ), the rate of response was modest. Thus, the lack of adequate response to divalproex sodium ER in the intent to treat analysis in our study was not likely to be due to sub-therapeutic doses.

Similarly, we found a statistically significant but a clinically modest reduction in CDRS depression ratings from baseline to endpoint. The mean CDRS score at endpoint of 30.8 indicated significant residual depression. These results are consistent with the observation that only $20 \%$ of subjects with depression were rated as much or very much improved on the depression CGI-I. Consistent with these results are those by Delbello et al. [14] who reported persistently elevated rating on the CDRS at endpoint in adolescents treated with divalproex despite statistically significant improvement in mania. In the 6month study of divalproex sodium conducted by Pavuluri et al. [12] there was a statistically significant reduction in CDRS scores but the mean score never fell below the clinical range of 25 [12]. Although Findling et al. [25] showed the greatest clinical response on the CDRS (from $31.7 \pm 14.0$ to $20.9 \pm 7.9$ ) associated with treatment with divalproex, this was a study of divalproex sodium combined with lithium carbonate.

The modest response to treatment with divalproex sodium ER monotherapy in our open label study of bipolar spectrum youth age $6-12$ is highly congruent with the recently published results [17] from a large, multisite, double blind, placebo controlled, randomized clinical trial of divalproex sodium ER that documented similarly modest response and failed to separate from placebo. Our 
study differed from this study in the younger age of the subjects ( 8.9 years versus 12.8 years) as the double blind study had more than one third of the subjects aged $14-17$. In addition, this study had a lower YMRS score at baseline versus the double blind study (26 verus 31 ) and an entry criterion of YMRS greater than 15 versus 20 . This study is novel in that it utilized divalproex extended release formulation, included bipolar spectrum youth, and included young subjects age 6 - 12, yet the findings are similar to the double blind trial.

Of note is that clinicians wishing to avoid weight gain in young children commonly seen in the second generation antipsychotic medications, four of which have FDA approval for use in bipolar youth, will also encounter weight gain with the use of divalproex extended release. The weight gain in this 8 week study was average $1.4 \pm$ $3.0 \mathrm{~kg}$.

These findings should be considered in the context of methodological limitations. This was an open trial of 18 subjects some of whom $(\mathrm{N}=6)$ may not have received therapeutic levels of medication. Our sample also included subjects receiving concomitant stimulant pharmacotherapy $(\mathrm{N}=1)$ and with conduct disorder $(\mathrm{N}=4)$ but in insufficient number to make meaningful inferences regarding response or tolerability. Although reports of adverse effects were common in our data, our assessment of adverse effects relied on spontaneous reports by subjects and their parents and reflect their occurrence if they were observed more than once during the trial. We also do not have systematic data describing prior medication trials in the population and cannot comment on either the impact of prior medication on the rate of improvement or weight change observed in this study.

Despite these limitations, this study suggests that treatment with divalproex sodium ER monotherapy was associated with poor tolerability and had modest therapeutic benefits in the management of symptoms of mania and depression in children with pediatric bipolar disorder. More work is needed to better define the role of divalproex sodium in the treatment of pediatric bipolar disorder alone or in combination with other thymoleptic treatments.

\section{CONCLUSION}

Divalproex sodium ER monotherapy treatment for youth with bipolar disorder demonstrated only modest improvement in symptoms of mania or depression in children in this 8 week open label study and weight gain was noted. Clinicians should look to other medications as first line treatments for pediatric bipolar disorder.

\section{ACKNOWLEDGEMENTS}

This study was partially supported by Abbott Laboratories, the Pediat- ric Psychopharmacology Council Fund, and the Susan G. Berk Endowed Fund for Juvenile Bipolar Disorder. We would like to acknowledge Meg Kotarski, MBA, and Eric Mick, ScD for their contributions to this study.

\section{REFERENCES}

[1] Faedda, G., Baldessarini, R., Suppes, T., Tondo, L., Becker, I. and Lipschitz, D. (1995) Pediatric-onset bipolar disorder: A neglected clinical and public health problem. Harvard Review of Psychiatry, 3, 171-195. doi:10.3109/10673229509017185

[2] Geller, B. and Luby, J. (1997) Child and adolescent bipolar disorder: A review of the past 10 years. Journal of the American Academy of Child and Adolescent Psychiatry, 36, 1168-1176. doi:10.1097/00004583-199709000-00008

[3] Biederman, J., Mick, E., Faraone, S.V., Spencer, T., Wilens, T.E. and Wozniak, J. (2000) Pediatric mania: A developmental subtype of bipolar disorder? Biological Psychiatry, 48, 458-466. doi:10.1016/S0006-3223(00)00911-2

[4] Wozniak, J., Biederman, J., Kiely, K., Ablon, S., Faraone, S., Mundy, E. and Mennin, D. (1995) Mania-like symptoms suggestive of childhood onset bipolar disorder in clinically referred children. Journal of the American Academy of Child and Adolescent Psychiatry, 34, 867-876. doi:10.1097/00004583-199507000-00010

[5] Geller, B., Craney, J.L., Bolhofner, K., Nickelsburg, M.J., Williams, M. and Zimerman, B. (2002) Two-year prospective follow-up of children with a prepubertal and early adolescent bipolar disorder phenotype. American Journal of Psychiatry, 159, 927-933. doi:10.1176/appi.ajp.159.6.927

[6] Strober, M., Schmidt-Lackner, S., Freeman, R., Bower, S., Lampert, C. and De Antonio, M. (1995) Recovery and relapse in adolescents with bipolar affective illness: A five-year naturalistic, prospective follow-up. Journal of the American Academy of Child and Adolescent Psychiatry, 34, 724-731. doi:10.1097/00004583-199506000-00012

[7] Pope, H.G., McElroy, S.L., Keck, P.E., Jr. and Hudson, J.I. (1991) Valproate in the treatment of acute mania. Archives of General Psychiatry, 48, 62-68. doi:10.1001/archpsyc.1991.01810250064008

[8] Bowden, C.L., Brugger, A.M., Swan, A.C., Calabrese, J.R., Janicak, P.G., Petty, F., Dilsaver, S.C., Davis, J.M., Rush, A.J., Small, J.G., Garza-Trevino, E.S., Risch, S.C., Goodnick, P.J. and Morris, D.D. (1994) Efficacy of divalproex vs lithium and placebo in the treatment of mania. Journal of the American Medical Association, 271, 918924. doi:10.1001/jama.1994.03510360044034

[9] Swann, A.C. (2001) Prediction of treatment response in acute mania: Controlled clinical trials with divalproex. Encephale, 27, 277-279.

[10] Kowatch, R.A., Suppes, T., Carmody, T.J., Bucci, J.P., Hume, J.H., Kromelis, M., Emslie, G.J., Weinberg, W.A. and Rush, A.J. (2000) Effect size of lithium, divalproex 
sodium, and carbamazepine in children and adolescents with bipolar disorder. Journal of the American Academy of Child and Adolescent Psychiatry, 39, 713-720. doi:10.1097/00004583-200006000-00009

[11] Wagner, K.D., Weller, E., Carlson, G.A., Sachs, G., Biederman, J., Frazier, J., Wozniak, P., Tracy, K., Weller, R. and Bowden, C.L. (2002) An open-label trial of divalproex in children and adolescents with bipolar disorder. Journal of the American Acadamey of Child and Adolescent Psychiatry, 41, 1224-1230. doi:10.1097/00004583-200210000-00012

[12] Pavuluri, M.N., Henry, D.B., Carbray, J.A., Naylor, M.W. and Janicak, P.G. (2005) Divalproex sodium for pediatric mixed mania: A 6-month prospective trial. Bipolar Disorders, 7, 266-273. doi:10.1111/j.1399-5618.2005.00204.x

[13] Scheffer, R.E., Kowatch, R.A., Carmody, T. and Rush, A.J. (2005) Randomized, placebo-controlled trial of mixed amphetamine salts for symptoms of comorbid ADHD in pediatric bipolar disorder after mood stabilization with divalproex sodium. The American Journal of Psychiatry, 162, 58-64. doi:10.1176/appi.ajp.162.1.58

[14] DelBello, M.P., Kowatch, R.A., Adler, C.M., Stanford, K.E., Welge, J.A., Barzman, D.H., Nelson, E. and Strakowski, S.M. (2006) A double-blind randomized pilot study comparing quetiapine and divalproex for adolescent mania. Journal of the American Academy of Child and Adolescent Psychiatry, 45, 305-313. doi:10.1097/01.chi.0000194567.63289.97

[15] Delbello, M.P., Schwiers, M.L., Rosenberg, H.L. and Strakowski, S.M. (2002) A double-blind, randomized, placebo-controlled study of quetiapine as adjunctive treatment for adolescent mania. Journal of the American Academy of Child and Adolescent Psychiatry, 41, 1216-1223. doi:10.1097/00004583-200210000-00011

[16] Rana, M., Khanzode, L., Karnik, N., Saxena, K., Chang, K. and Steiner, H. (2005) Divalproex sodium in the treatment of pediatric psychiatric disorders. Expert Review of Neurotherapeutics, 5, 165-176. doi:10.1586/14737175.5.2.165

[17] Wagner, K.D., Redden, L., Kowatch, R.A., Wilens, T.E., Segal, S., Chang, K., Wozniak, P., Vigna, N.V., Abi-Saab, W. and Saltarelli, M. (2009) A double-blind, randomized, placebo-controlled trial of divalproex extended-release in the treatment of bipolar disorder in children and adolescents. Journal of the American Academy of Child and Adolescent Psychiatry, 48, 519-532.

\section{doi:10.1097/CHI.0b013e31819c55ec}

[18] Young, R., Biggs, J., Ziegler, V. and Meyer, D. (1978) A rating scale for mania: Reliability, validity and sensitivity. British Journal of Psychiatry, 133, 429-435. doi:10.1192/bjp.133.5.429

[19] Youngstrom, E.A., Danielson, C.K., Findling, R.L., Gracious, B.L. and Calabrese, J.R. (2002) Factor structure of the young mania rating scale for use with youths ages 5 to 17 years. Journal of Clinical Child \& Adolescent Psychology, 31, 567-572. doi:10.1207/S15374424JCCP3104_15

[20] Lachar, D., Bailley, S.E., Rhoades, H.M., Espadas, A., Aponte, M., Cowan, K.A., Gummattira, P., Kopecky, C.R. and Wassef, A. (2001) New subscales for an anchored version of the brief psychiatric rating scale: Construction, reliability, and validity in acute psychiatric admissions. Psychological Assessment, 13, 384-395. doi:10.1037/1040-3590.13.3.384

[21] National Institute of Mental Health (1985) CGI (Clinical Global Impression) Scale-NIMH. Psychopharmacology Bulletin, 21, 839-844.

[22] Wagner, B.M. (1997) Family risk factors for adolescent suicidal behavior. Psychological Bulletin, 121, 246-298.

[23] Pavuluri, M.N., Herbener, E.S. and Sweeney, J.A. (2004) Psychotic symptoms in pediatric bipolar disorder. Journal of Affective Disorders, 80, 19-28. doi:10.1016/S0165-0327(03)00053-3

[24] Del Bello, M.P. and Geller, B. (2001) Review of studies of child and adolescent offspring of bipolar parents. Bipolar Disorders, 3, 325-334. doi:10.1034/j.1399-5618.2001.30607.x

[25] Findling, R.L., McNamara, N.K., Gracious, B.L., Youngstrom, E.A., Stansbrey, R.J., Reed, M.D., Demeter, C.A., Branicky, L.A., Fisher, K.E. and Calabrese, J.R. (2003) Combination lithium and divalp roex sodium in pediatric bipolarity. Journal of the American Academy of Child and Adolescent Psychiatry, 42, 895-901. doi:10.1097/01.CHI.0000046893.27264.53

[26] Findling, R.L., McNamara, N.K., Youngstrom, E.A., Stansbrey, R., Gracious, B.L., Reed, M.D. and Calabrese, J.R. (2005) Double-blind 18-month trial of lithium versus divalproex maintenance treatment in pediatric bipolar disorder. Journal of the American Academy of Child and Adolescent Psychiatry, 44, 409-417. doi:10.1097/01.chi.0000155981.83865.ea 